aimed at young people. Discussion of potential solutions centred on the role of industrial responsibility, the need for government intervention to curb sugar consumption and the role that taxation could play.

Conclusion SSBs received substantial media attention in mainstream UK national newspapers during 2015 and 2016. Public health media advocacy was prominent throughout, with a growing consensus that SSBs are bad for health, government intervention is required and taxation may be an important policy measure. Our findings suggest that the reporting of the SSB policy debate may have helped shape the public health policy agenda on sugar consumption.

\section{P62 1 THE CHALLENGES OF USING SOCIAL THEORY TO UNDERPIN DIETARY INTERVENTIONS}

S Chambers. MRC/CSO Social and Public Health Sciences Unit, University of Glasgow, Glasgow, UK

\subsection{6/jech-2017-SSMAbstracts. 163}

Background Behavioural approaches to designing dietary interventions can over-emphasise the role of reasoned, individual decision-making, neglecting contextual factors, resulting in suboptimal interventions. This presentation critically analyses the utility of social theory (structuration theory) in the design of dietary interventions.

Methods This study uses the example of designing, implementing and evaluating a school-based dietary intervention underpinned by structuration theory. Structuration theory describes the interplay of societal structures and individual agency that result in social practices and patterns. Qualitative data collected with children $(n=124)$, parents $(n=17)$ and teachers $(n=8)$ were analysed identifying key structures (meanings and normative rules, and resources) as a framework to understand dietary practices. Identified rules and resources provided a basis on which to design an intervention. A process evaluation included interviews with school staff $(n=4)$ and baseline and follow-up data collected from children $(n=137)$. No feedback was returned from parents. The process evaluation examined adherence, fidelity, and acceptability, and provided an indication of effect.

Results Key rules and resources identified in qualitative work were valuing food cooked by family members, cooking inexperience, food misconceptions and rules, lack of food vocabulary, home food provision, school meal and drink provision, curriculum, teacher training, school funding, and national legislation. These findings were translated into an intervention that provided water bottles and water, classroom-based teaching around the curriculum that incorporated the development of cooking skills, a food vocabulary, homework exercises, and teacher training. Areas that could not be addressed included home food provision, school meal provision, school funding and national legislation. The intervention was acceptable to children and largely acceptable to teachers, but timing pressures meant not all exercises could be covered. Improvements were reported around children's drinks.

Conclusion Intervention components were largely limited to impacting individual level agency. For university-based research teams, structural components remain difficult to modify. Interventions seeking to impact at multiple levels must work with influential stakeholders working at structural levels, who can impact on long term processes. Social theory can help identify structural and individual level opportunities through which to focus dietary interventions, but the small scale approaches that predominate must be re-thought to increase intervention impact.

\section{P63 DIET@NET: DEVELOPMENT OF THE NUTRITOOLS WEBSITE FOR DIETARY ASSESSMENT}

JE Cade*, M Warthon-Medina, J Hooson, N Hancock. Nutritional Epidemiology Group, School of Food Science and Nutrition, University of Leeds, Leeds, UK

10.1136/jech-2017-SSMAbstracts. 164

Background Selection of validated dietary assessment tools (DAT) is challenging. Researchers are often unable to identify available tools or gain access to them. Development of new tools is difficult, due to lack of appropriate guidance; inability to identify which foods to include and the need to link these to food composition tables. The DIET@NET (Dietary Assessment tools network) partnership aims to create a dietary assessment website to provide guidelines for selection of tools, with access to previously validated questionnaires. In addition, to create a novel platform for creation of new food questionnaires.

Methods Development of the Nutritools website was divided into 3 strands. 1) Creation of Best Practice Guidelines (BPG) for dietary assessment; generated with a Delphi method to generate consensus amongst expert views. 2) Creation of an interactive DAT e-library, with tools being identified through a systematic review of systematic reviews. 3) Creation of an online platform to create new questionnaires.

Results The Delphi consultation generated 43 BPG and a summary of the strengths and weaknesses of the dietary assessment methods. The interactive BPG enables researchers to choose the most appropriate dietary assessment tool. The systematic review of systematic reviews resulted in identification of 62 tools validated in UK populations. Detailed information on these tools is provided in the DAT e-library. Visual representation of this data through two interactive plots (bubble and summary plots) allows researchers to compare between the DATs. Only 9 of the tools date from 2010 onwards; many tools identified are no longer available or need updating. Existing validated food questionnaires have been transformed and updated from paper-based to web-based using the novel FQC. Foods are mapped to the latest food composition database. In addition, new online food questionnaires can be created through guided food selection with database mapping. New tools will support online data entry and analysis. At present, the FQC only provides UK dietary assessment tools and databases but it has the capability to allow for international databases and tools to be added.

Conclusion The Nutritools website, www.nutritools.org provides a central resource for researchers undertaking studies which require dietary measurement. By providing guidance and access to validated DATs, the quality, consistency and comparability of dietary assessment in public health and epidemiology can be improved. The Food Questionnaire Creator, is a unique feature of the site which will encourage a more standardised approach to dietary assessment. 